\title{
Design, preparation and application of a Pirkle-type chiral stationary phase for enantioseparation of some racemic organic acids and molecular dynamics studies
}

\author{
Reşit Çakmak $^{\oplus 1}$, Selami Ercan ${ }^{\oplus 2}$, Murat Sünkürr ${ }^{\oplus 1}$, Hayrullah Yılmaz ${ }^{\oplus 3}$ and \\ Giray Topal $^{{ }^{* 3}}$
}

\author{
${ }^{I}$ Department of Chemistry, Faculty of science and Art, Batman University, 72100, Batman, Türkiye, \\ ${ }^{2}$ Department of Nursing, School of Health Science, Batman University, 72060, Batman, Türkiye \\ ${ }^{3}$ Department of Chemistry, Faculty of Education, Dicle University, 21280, Diyarbakır, Türkiye
}

(Received July 17, 2017; Revised September 10, 2017; Accepted September 11, 2017)

\begin{abstract}
This study consists of two parts. In the first part of the study; a Pirkle-type chiral stationary phase was prepared by synthesizing an aromatic amine derivative of $(R)$-2-amino-1-butanol as a chiral selector and binding to L-tyrosine-modified cyanogen bromide (CNBr)-activated Sepharose 4B and then, packed into the separation column. The chromatographic performance of the separation column was evaluated with racemic mandelic acid and 2-phenylpropionic acid by using phosphate buffers at three different $\mathrm{pHs}$ as mobile phase. In the resolution processes, the prepared solutions were loaded onto the separation column at two different concentrations and at three different $\mathrm{pHs}$ for each racemic organic acid, separately. Enantiomeric excess (ee\%) of the eluates was determined on CHIRALPAK AD-H chiral analytical column by HPLC. The maximum ee\% for mandelic acid and 2-phenylpropionic acid was determined to be 60.84 and 27.4, respectively. Separation factors $\left(\mathrm{k}_{1}, \mathrm{k}_{2}, \alpha\right.$, and Rs) were calculated for each acid. The structures of the obtained compounds were characterized using the spectroscopic methods (NMR, and elemental analysis). In the second part of the study; enantioselective interactions between the prepared CSP and the analytes have been widely studied by docking, molecular dynamics simulation and quantum mechanical computation methods. The reason of column eluation of rac-2-phenylpropionic acid with lower enantiomeric yield was explained by these techniques.
\end{abstract}

Keywords: Pirkle-type chiral stationary phase; enantioseparation; molecular dynamics; docking. (O2017 ACG Publications. All rights reserved.

\section{Introduction}

Liquid chromatographic separation of racemic compounds on chiral stationary phases (CSPs) is one of the research topics in chemistry and has become increasingly important recently, since the enantiomers of chiral compounds have different pharmacological or toxicological activities in living

* Corresponding author: E-Mail: giray.topal@ gmail.com, Phone: +90 41224883 99; Fax: +90 4122488257. 
systems. Therefore, the separation of racemates is required for applications in many different areas such as the pharmaceutical industry, environmental chemistry, food chemistry and agriculture. ${ }^{1-6}$ In the chiral resolution of a racemic mixtures in chemistry, the various methods such as asymmetric synthesis, chromatographic separation, chemical or enzymatic kinetic resolution, and diastereomeric crystallization were utilized to acquire selectively the desired enantiomer. Among the methods used for the chiral resolution, enantio separation by HPLC using CSPs is currently the most popular one. ${ }^{7-12}$ For this reason, significant effort was devoted to the development of new effective CSPs in recent years. For this purpose, various kinds of CSPs have been developed and tested so far. ${ }^{13-16} \alpha$-Hydroxy acids (AHAs) are naturally occurring carboxylic acids found in many foods, and constitute one of the most important classes of chiral molecules. One of AHAs, mandelic acid (MA) generally exists as a racemic mixture, and applies widely as a synthetic intermediate. On the other hand, there is an increasing demand for the chiral resolution of its racemate. $(R)$-MA is used as a precursor for the preparation of some the antibiotics such as penicillin and cephalosporin. The 2-arylpropionic acids (2APAs) are an important subgroup within the class of Nonsteroidal anti-inflammatory drugs (NSAIDs), and indicate their pharmacological activity mainly in the $(S)$-enantiomer. ${ }^{17-22}$ Computational methods are important tools for determining systems' microscopic analysis such as atomic and molecular properties of molecules which are problematic or impossible to define by experimental procedures, especially in complex chromatography-like systems. Molecular dynamics (MD) simulation and quantum mechanical computation can provide valuable information about behavior of chiral discrimination of racemic compounds. Enantioselectivity of enzymes and also CSPs have been widely studied. Bikadi and Hazai studied chiral preference of CYP2C enzymes with molecular docking and molecular dynamics methods. ${ }^{23}$ Cann and et al. performed computational methods to define the mechanism of chiral selectivity of Whelk-O1 CSP by docking different analytes to CSPs ${ }^{24}$ and they also used MD for optimization of CSPs of the Whelk-O1. ${ }^{25}$ Yang et al. used molecular mechanics and QSRR methods for the discrimination of organophosphonate derivatives on a pirkle-type CSPs. In another study, Jiang and Hu ran a molecular dynamics simulation study for chiral separation of racemic phenylglycines in thermolysin crystal.

Here, we report the synthesis and application of a Pirkle-type CSP for enantio separation of racMA and 2-phenylpropionic acid (2-PPA). In this application, ee\% of the eluates was determined on commercially available CHIRALPAK AD-H chiral analytical column by HPLC. In the scope of present study, we used molecular docking, molecular dynamics (MD) simulation and quantum mechanical computational methods to obtain an accurate picture of enantioselective interactions between prepared Pirkle-type CSP and racemic organic acids. In the resent study, the prepared Pirkle-type CSP was synthesized to according to MSc Thesis ${ }^{33}$ in 2010. In the mentioned MSc thesis work, the same CSP, prepared by our group, was used for the chiral resolution of racemic mixture of 3-hydroxybutanoic acid (3-HBA), and the maximum enantiomeric purity was found as $11.4 \%$ for 3-HBA. In this study, the chiral discrimination processes of racemic mixtures of two the different organic acids, instead of 3-HBA, were carried out and ee\% of the eluates was differently determined on CHIRALPAK AD-H by HPLC, instead of the calculation with a known formula by determining of the rotation angles of the fractions by a UV spectrophotometer. Additionally, the enantioselective interactions between the prepared CSP and the analytes have been extensively investigated.

\section{Experimental}

All chemicals used in this work were obtained from Sigma-Aldrich and Merck. They were of analytical grade and used as received without any further purification. A $1.0 \mathrm{~cm}$ x $20.0 \mathrm{~cm}$ (IDXL) Luerlock, non-jacketed liquid chromatography column was purchased from Sigma-Aldrich, and utilized for packing into of the prepared CSP. Flow rate of the eluates was adjusted with a peristaltic pump (Watson Marlow-323). The concentration of the eluates was determined with a UV spectrophotometer (PerkinElmer, Lambda 35). The ${ }^{1} \mathrm{H}$ and ${ }^{13} \mathrm{C}$ NMR spectra of the chiral selector were recorded with a NMR spectrometer (Bruker AC $400 \mathrm{MHz}$ ). Elemental analyses were carried out with a Thermo Scientific FLASH 2000 instrument. LC-MS analyses were performed by a Shimadzu LC/MS 8040 instrument. The rotation angels were recorded with a Polarimeter (Atago Dr-21949). The melting points were measured by a Barnstead Electro thermal 9100. The optical purity of all the eluates was determined with a HPLC apparatus (Agilent 1200) and by using CHIRALPAK AD-H analytical column which had $250 \mathrm{~mm} \times 4.6$ $\mathrm{mm}$ i.d. dimensions with $5 \mu \mathrm{m}$ particle sizes and CHIRALPAK guard cartridge. Distilled water was 
purified by using a Millipore MilliQ water system. 2D structures of molecules were drawn by an easy to use chemical drawing program Marvin. ${ }^{26}$ Molecular visualization program DS Visualizer ${ }^{27}$ was used for converting 2D structures of molecules to 3D structures. AMBER v.12 $2^{28}$ suite program was used for molecular dynamics calculations while Autodock4 (v. 4.2.6) ${ }^{29}$ and its visualization program MGL Tools were used for molecular dockings. All quantum mechanical computations were carried out with Gaussian 09 program. ${ }^{30}$ Chimera and DS Visualizer programs were used for simulations of structures and analysis. ${ }^{31}$ The stationary parts of chiral phase acted as $-\mathrm{CH}_{3}$ (it does not affect the stereoselectivity of branch in interaction with analytes) which bound to ester oxygen (Scheme 1). CSP was optimized with semi-empirical am1 method while $(R)$ and $(S)$ configurations of MA and 2-PPA were optimized at MP2/6-31+G (d) level. After optimization, the force field parameters of molecules were created by antechamber and parmchk module of Amber suite program. Topology and coordinate files were created by Xleap module for implicit model without a boundary condition. CSP molecule is minimized by 1000 steps of Steepest Descent and followed by 1000 steps of Conjugate Gradient method. Afterwards, system was heated to $700 \mathrm{~K}$ from $0 \mathrm{~K}$ in seven steps with a 0.5 fs time step of totally 175 ps of simulation time. Production simulation was carried out with a constant temperature of $700 \mathrm{~K}$ by using a weak-coupling algorithm. Hydrogen bonds constrained with Shake algorithm and MD simulation was carried $10 \mathrm{~ns}$ time length. A structure of CSP having minimum energy was selected from molecular dynamics simulations and minimized for docking procedure.

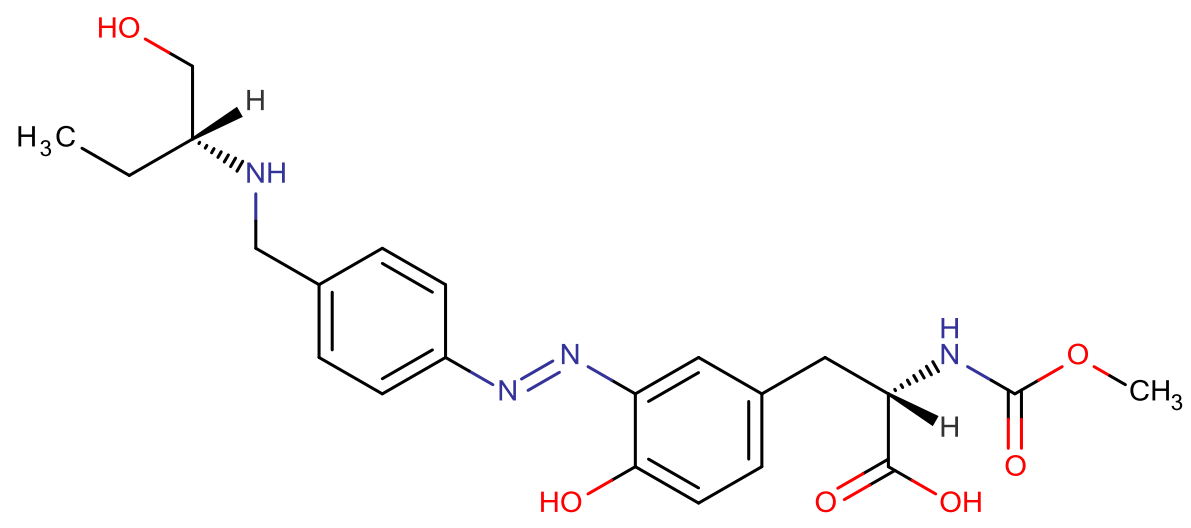

Scheme 1. Modified structure of CSP used for computational studies

Docking studies (flexible ligand-rigid receptor (CSP)) were performed by Autodock4. All the water molecules left from MD simulations in the CSP are deleted for docking procedure. Gasteiger charges are added to atoms after assigning atom types as Autodock 4 atom types. Lamarckian Genetic Algorithm was employed for docking with the settings of 150 individuals in a population, maximum energy evaluations of 2500 000, maximum generations of 27000 and 50 docking runs for each ligand. Receptor and ligand file preparation was done by MGL Tools. Interactions of analytes with CSP were analyzed with MGL Tools, Chimera and DS Visualizer. Complexes are optimized with Gaussian 09. Four complexes were firstly optimized by semi-empirical AM1 method. Last optimization was carried out by B3LYP/6-31+G (d). ${ }^{32}$ Basis set of DFT method.

\subsection{Chemistry}

\subsubsection{General Procedure for Synthesis of Chiral Selector (4): ${ }^{33-35}$}

Preparation of $N$-p-nitrobenzyl-(R)-2-amino-1-butanol (3): $4.46 \mathrm{~g}$ (50 mmol) $(R)$-2-amino-1butanol (2), $1.3 \mathrm{~g}$ (12.3 mmol) $\mathrm{Na}_{2} \mathrm{CO}_{3}$ and $2.7 \mathrm{~g}(12.5 \mathrm{mmol}) p$-nitrobenzyl bromide (1) in $100 \mathrm{~mL}$ benzene were placed in a $250 \mathrm{~mL}$ two-necked round bottomed flask equipped with an Dean-Stark apparatus, which applies to separate water from refluxing benzene. The mixture was refluxed by stirring at $110{ }^{\circ} \mathrm{C}$ for $12 \mathrm{~h}$ in an oil bath under dry $\mathrm{N}_{2}$. Afterwards, it was cooled, filtered off and, then the solvent was removed by evaporation. The remaining crude product was crystallized from benzene/ethanol (1:1). 
$N$-p-nitrobenzyl-(R)-2-amino-1-butanol (3): White crystal, yield, $70 \%$, M.P. $113{ }^{\circ} \mathrm{C},[\alpha]_{D}^{25}=-12.4$ (c:0.5, in ethanol); ${ }^{1} \mathrm{H}$ NMR $\left(\mathrm{CDCl}_{3}\right) \delta: 0.95(\mathrm{t}, 3 \mathrm{H}, J=8 \mathrm{~Hz}), 1.44-1.62(\mathrm{~m}, 2 \mathrm{H}, \mathrm{AB}$ system), 1.98 (broad s, $1 \mathrm{H}$ ), 2.61-2.65 (m, $1 \mathrm{H}), 3.37-3,41$ and 3,66-3.70 (dd, $\left.2 \mathrm{H} \quad J_{l}=6,8 \mathrm{~Hz} ; J_{2}=4,4 \mathrm{~Hz}\right), 3.94\left(\mathrm{dd}, 2 \mathrm{H} J_{l}=2,4 \mathrm{~Hz}\right.$; $\left.J_{2}=1,4 \mathrm{~Hz}\right), 7.53(\mathrm{~d}, 2 \mathrm{H}, J=8,4 \mathrm{~Hz}), 8.19(\mathrm{~d}, 2 \mathrm{H}, J=8,4 \mathrm{~Hz}) .{ }^{13} \mathrm{C} \mathrm{NMR}\left(\mathrm{CDCl}_{3}\right) \delta: 10.35,24.22,50.30$, 59.98, 62.81, 123.70, 128.65, 147.08, 148.22. (Figures $\mathrm{S} 7 \mathrm{a}$ and $\mathrm{S} 7 \mathrm{~b}$ ) Anal calcd for $\mathrm{C}_{11} \mathrm{H}_{16} \mathrm{~N}_{2} \mathrm{O}_{3}(224.26)$ : C, 58.91; H, 7.19; N, 12.49; O, 21.40. Found: C, 58.77; H, 7.25; N, 12.68; O, 21.28.

Preparation of N-p-aminobenzyl-(R)-2-amino-1-butanol (4): $1.2 \mathrm{~g} 3$ was dissolved by stirring in $100 \mathrm{~mL}$ ethanol, and then $0.15 \mathrm{~g} \mathrm{Pd} / \mathrm{C}$ was added to the stirred solution. The obtained mixture was heated at $65^{\circ} \mathrm{C}$ for $30 \mathrm{~min}$. Afterwards, $25 \mathrm{~mL}$ hydrazine hydrate was added drop wise to the mixture. It was refluxed at $80{ }^{\circ} \mathrm{C}$ for $3 \mathrm{~h}$. At the end of this time, the hot mixture was filtered immediately and the ethanol was evaporated. The remaining crude product was crystallized from benzene.

$N$-p-aminobenzyl-(R)-2-amino-1-butanol (4): Yellow crystal, yield, $80 \%$, M.P. $73{ }^{\circ} \mathrm{C},[\alpha]_{D}^{25}=-17.6$ (c:1.2, in ethanol); ${ }^{1} \mathrm{H}$ NMR $\left(\mathrm{CDCl}_{3}\right) \delta: 0.93-198(\mathrm{~m}, 9 \mathrm{H}),, 3.98(\mathrm{~m}, 2 \mathrm{H}), 6.72(\mathrm{~d}, 2 \mathrm{H}, J=8,4 \mathrm{~Hz}), 7.09$ (s, $1 \mathrm{H}$,broad), 7.28-7.38 (s, 2H, broad), 7.65 (d, $2 \mathrm{H}, J=8 \mathrm{~Hz}) .{ }^{13} \mathrm{C} \mathrm{NMR}\left(\mathrm{CDCl}_{3}\right) \delta: 14.13,19.76,22.71$, 29.72, 30.05, 114.75, 130.16, 160.99. (Figures S8a and S8b). HRMS for $\mathrm{C}_{11} \mathrm{H}_{18} \mathrm{~N}_{2} \mathrm{O}$ : calc'd $\mathrm{m} / z: 195.1447$; found $m / z: 195.1477$.

\subsubsection{General Procedure for Preparation of the Pirkle-type CSP 9: ${ }^{33-34}$}

$5.0 \mathrm{~g}$ activated Sepharose 4B (5) was swelled out by stirring in $25 \mathrm{~mL}$ distilled water, and then filtered, washed with $250 \mathrm{~mL}$ distilled water and $100 \mathrm{~mL} \mathrm{NaHCO}_{3}$ buffer $(0.2 \mathrm{M}, \mathrm{pH} 10.0)$ on a Buchner funnel, respectively. The remaining solid was placed in a $100 \mathrm{~mL}$ beaker, and $20 \mathrm{~mL}$ of L-tyrosine (6) solution $\left(4 \mathrm{mg} \cdot \mathrm{mL}^{-1}\right)$ was added by stirring magnetically for $2 \mathrm{~h}$ at $+4{ }^{\circ} \mathrm{C}$. Then, it was allowed for $18 \mathrm{~h}$ at the same temperature. In the end of the time, it was washed with $100 \mathrm{~mL} \mathrm{NaHCO}_{3}$ buffer $(0.2 \mathrm{M} \mathrm{pH} 8.8)$ on a Buchner funnel again, consequently 6 was coupled with (5). $60 \mathrm{mg} 4$ was dissolved in $10 \mathrm{~mL} 1 \mathrm{~N}$ HCl. $5 \mathrm{~mL}$ of $\mathrm{NaNO}_{2}$ solution $\left(20 \mathrm{mg} \cdot \mathrm{mL}^{-1}\right)$ was added slowly to this solution by stirring at $0{ }^{\circ} \mathrm{C}$. The diazo compound $(8)$ was poured into $45 \mathrm{~mL}$ suspension of 7. The $\mathrm{pH}$ of the mixture was adjusted to 9.5 with $1 \mathrm{~N} \mathrm{NaOH}$, and then the suspension was stirred for $4 \mathrm{~h}$ at room temperature. The yellow suspension (9) was washed with $750 \mathrm{~mL}$ distilled water and $300 \mathrm{~mL}$ phosphate buffer (PBS) (0.2 M pH 6.0) on a Buchner funnel, respectively, and CSP 9 was finally prepared. It was packed into the separation column and equilibrated with the same PBS by a peristaltic pump to use in the resolution processes.

\subsection{Resolution and Determination of ee\% by HPLC}

\subsubsection{General Procedure for Resolution of Racemic Organic Acids on the Separation Column}

All test solutions containing racemic organic acids were prepared in two different concentrations in $0.2 \mathrm{M}$ PBS for each $\mathrm{pH}$ values. At three different $\mathrm{pH}$, each racemic organic acid were loaded onto the separation column, separately. The studies were conducted at laboratory temperature. The elution was carried out with appropriate PBS at the studied $\mathrm{pH}$. At the each $\mathrm{pH}$ value, 12 eluates were taken, and the elution volume of each eluate was $3 \mathrm{~mL}$. Absorbance value of each eluate was determined by UV. It was observed that the organic acids were generally collected in the $8^{\text {th }}, 9^{\text {th }}$ and $10^{\text {th }}$ tubes (Table S1). In this section, after each resolution process, the separation column was renewed by washing with $1 \mathrm{~N} 100 \mathrm{~mL}$ $\mathrm{HCl}$ solution, hence amine groups of the chiral selector at CSP were returned into non-ionic form. Then, it was equilibrated with appropriate elution buffer (100 mL $0.2 \mathrm{M} \mathrm{PBS})$. Thus, the resolution column became ready to use in another resolution process.

\subsubsection{General Procedure for Determination of ee\% of Eluates}

The enantiomers of organic acids in the eluates were in the form of salt in PBS. For this reason, the solutions in the fractions were acidified with $1 \mathrm{M} \mathrm{HCI}$ solution to return into acid form and, then it was extracted with diethyl ether ( 3 times $3 \mathrm{~mL}$ ), consequently the organic acids were taken to the ether phase from the aqueous phase. The ether was evaporated and $2 \mathrm{~mL}$ of $\mathrm{n}$-hexane/2-PrOH (50:50 v/v) was 
added to the residue in each tube. After that, the solutions were taken into vials. Ee \% of eluates was determined by using Chiralpak AD-H analytical column by HPLC apparatus with a UV detector (Table S2). The retention times of $(S)$ and $(R)$-enantiomers for MA and 2-PPA were separately determined. The retention times for $(S)$ and $(R)$-enantiomer of MA and were found as 8.3 and 9.6 minutes, respectively. ${ }^{36}$ The retention times for $(S)$ and $(R)$-enantiomer of 2-PPA were 7.6 and 8.3 minutes, respectively. The retention times of the enantiomers $\left(t_{R 1}\right.$ and $\left.t_{R 2}\right)$ were utilized to determine the capacity factors of first and second eluted enantiomers, $k_{1}^{\prime}$ and $\mathrm{k}_{2}^{\prime}$, respectively, by use of the equations $k_{1}^{\prime}=\left[\mathrm{t}_{1}-\mathrm{t}_{0}\right] / \mathrm{t}_{0}$ and $k_{2}^{\prime}=\left[\mathrm{t}_{2}-\right.$ $\left.\mathrm{t}_{0}\right] / \mathrm{t}_{0}$. As for the separation factor $(\alpha)$ was determined by using the equation $\alpha=k_{2}^{\prime} / k_{1}^{\prime}$. The resolution factor $(R s)$ was determined by using the equation $R s=1.18\left[\mathrm{t}_{\mathrm{R} 2}-\mathrm{t}_{\mathrm{R} 1}\right] /\left[\mathrm{W}_{10.5}+\mathrm{W}_{20.5}\right]$ where $\mathrm{W}_{10.5}$ and $\mathrm{W}_{20.5}$ are the corresponding peak width measured on half height. ${ }^{37}$

\section{Results and Discussion}

\subsection{Chemistry}

In this study, a chiral selector $\mathbf{4}$ was prepared in good yield with reduction of the compound $\mathbf{3}$ in the presence of $\mathrm{Pd} / \mathrm{C}$ in ethanol for 3 hours (Scheme 2). The compound 3 was synthesized with the reaction of $(R)$-2-amino-1-butanol (2) and $N$-p-nitrobenzyl bromide (1) in the presence sodium carbonate in benzene with dean stark apparatus for $12 \mathrm{~h}$. The structures of compounds were explained on the basis of spectral data (NMR).

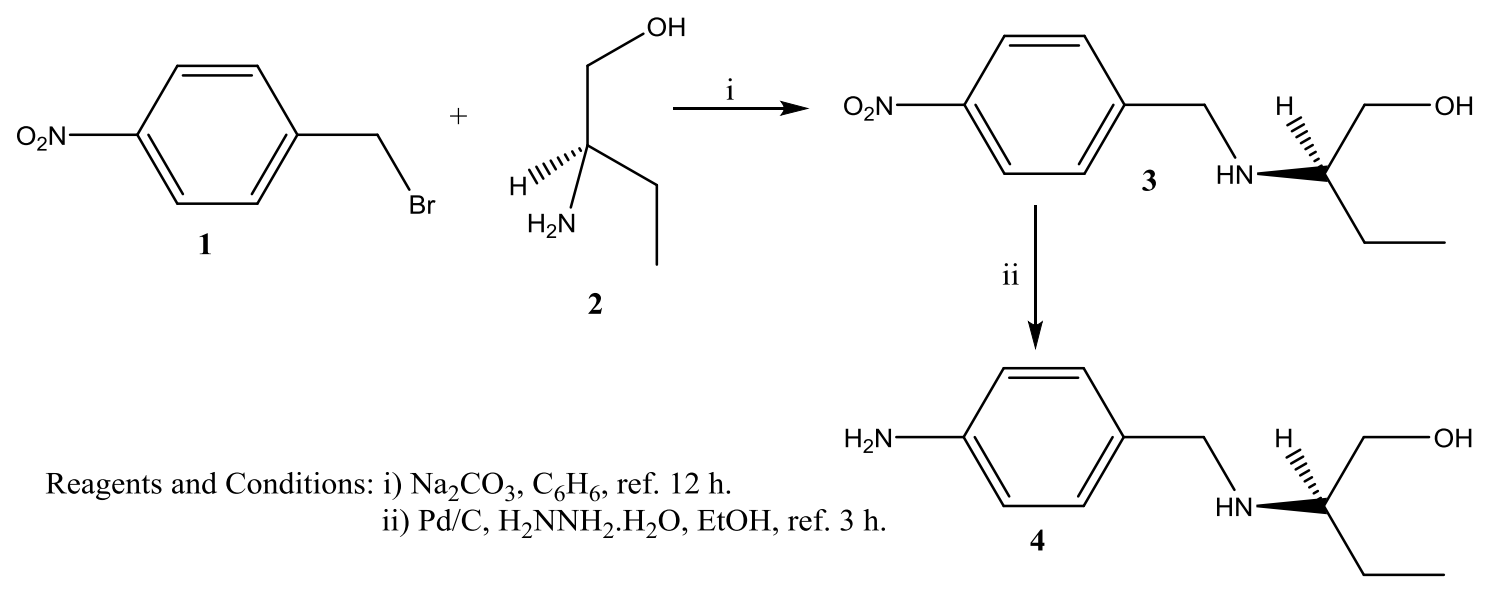

Scheme 2. Synthetic pathway of the aromatic amine derivative 4

Pirkle-type CSPs was generally prepared by immobilizing different amino acid derivatives on an inert chromatographic support, typically the silica gel. ${ }^{38-40}$ In present study, $\mathrm{CNBr}$-activated Sepharose 4B (5) was used instead of silica as a matrix and L-tyrosine (6) was used as a spacer arm. 6 was covalently bounded to $\mathbf{5}$. An excess of $\mathbf{6}$ solution was then added to completely react with imin groups of $\mathbf{5}$ to give amide derivative of 7 in a one-pot method and it was washed with distilled water for removal of impurities. Then, 4 as a $\pi$-basic chiral selector was diazotized in the presence of $\mathrm{HCI} / \mathrm{NaNO}_{2}$ at $0{ }^{\circ} \mathrm{C}$, and then bound to the $o$-position of phenyl ring of 6 linked to 7 and washed again with distilled water. The color of chiral gel (9) was changed to light yellow which indicated that diazotization reaction was successfully performed (Scheme 3). 


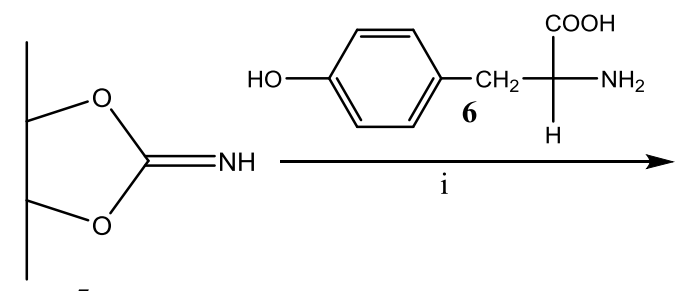

5
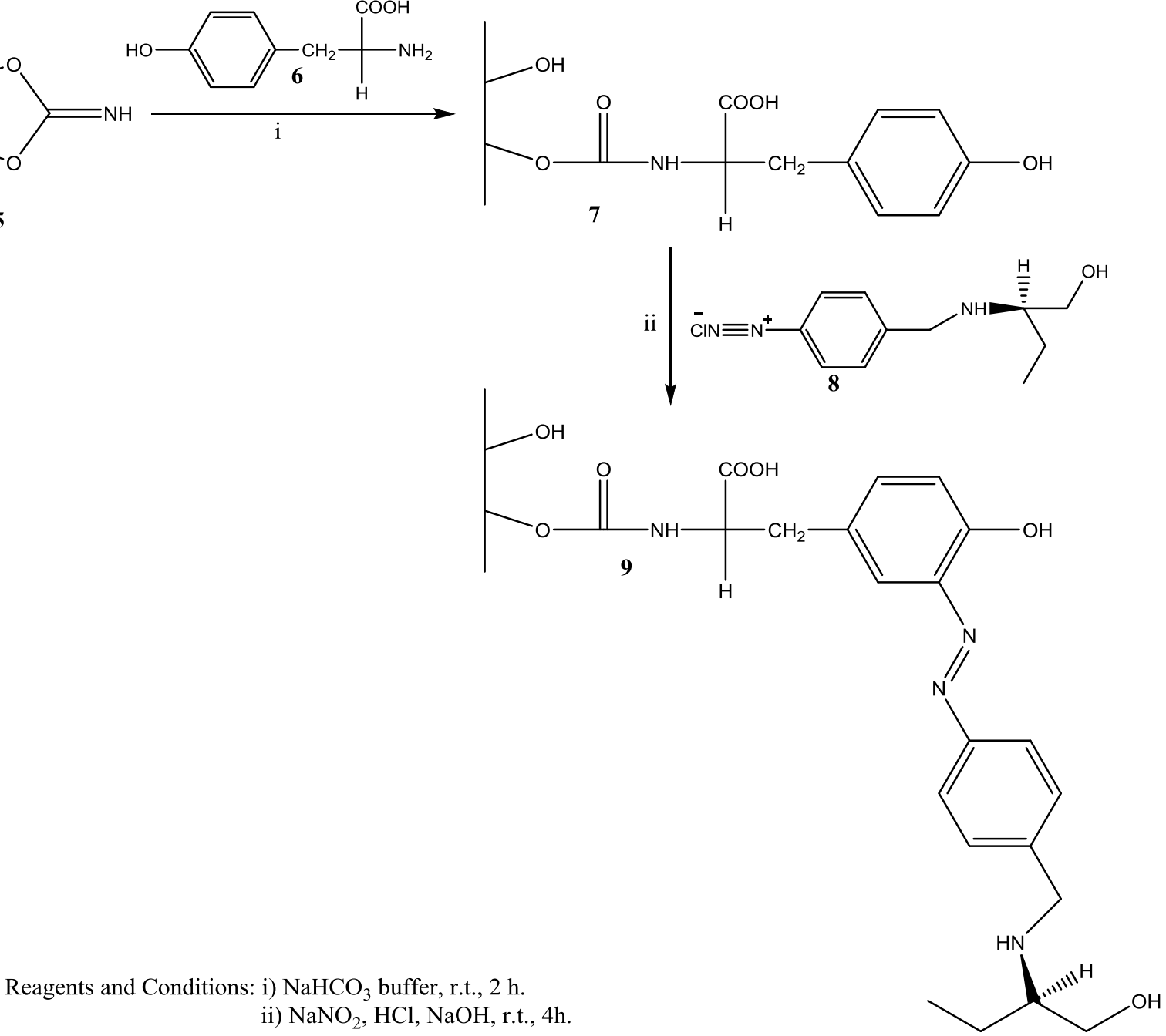

Scheme 3. Synthetic pathway of an aromatic amine derivative-based CSP 9

\subsection{Chiral Separation}

For each racemic organic acid, the resolution processes were performed in six series, in total, at two different concentrations for each $\mathrm{pH}$ values, and at three different $\mathrm{pHs}$ on the separation column. The maximum $e e \%$ for $r a c-M A$ was determined at $\mathrm{pH} 6.0$ for a sample containing $3 \mathrm{mg} \cdot \mathrm{mL}^{-1}$, and $9^{\text {th }}$ fraction compared to the others (Figure 1). The ee \% was found to be $60.84(R) \%$. Thus, it was found that the optimum binding amount is $3 \mathrm{mg} \cdot \mathrm{mL}^{-1}$, and the optimum $\mathrm{pH}$ is 6.0 (Figure $\mathrm{S} 1$ ).

The $e e \%$ became prominent in favor of the $(R)$-enantiomer of MA. The maximum $e e \%$ for $r a c$ 2-PPA was at $\mathrm{pH} 8.0$, a sample containing $5 \mathrm{mg}^{-\mathrm{mL}^{-1}}$, and $10^{\text {th }}$ fraction compared (Figure 2). The ee \% was found to be $27.4(S) \%$. Thus, it was found that, the optimum binding amount was $5 \mathrm{mg} \mathrm{mL}^{-1}$, and the optimum $\mathrm{pH}$ was 8.0. The ee\% became prominent in favour of the (S)-enantiomer of 2-PPA (Figure S2). 


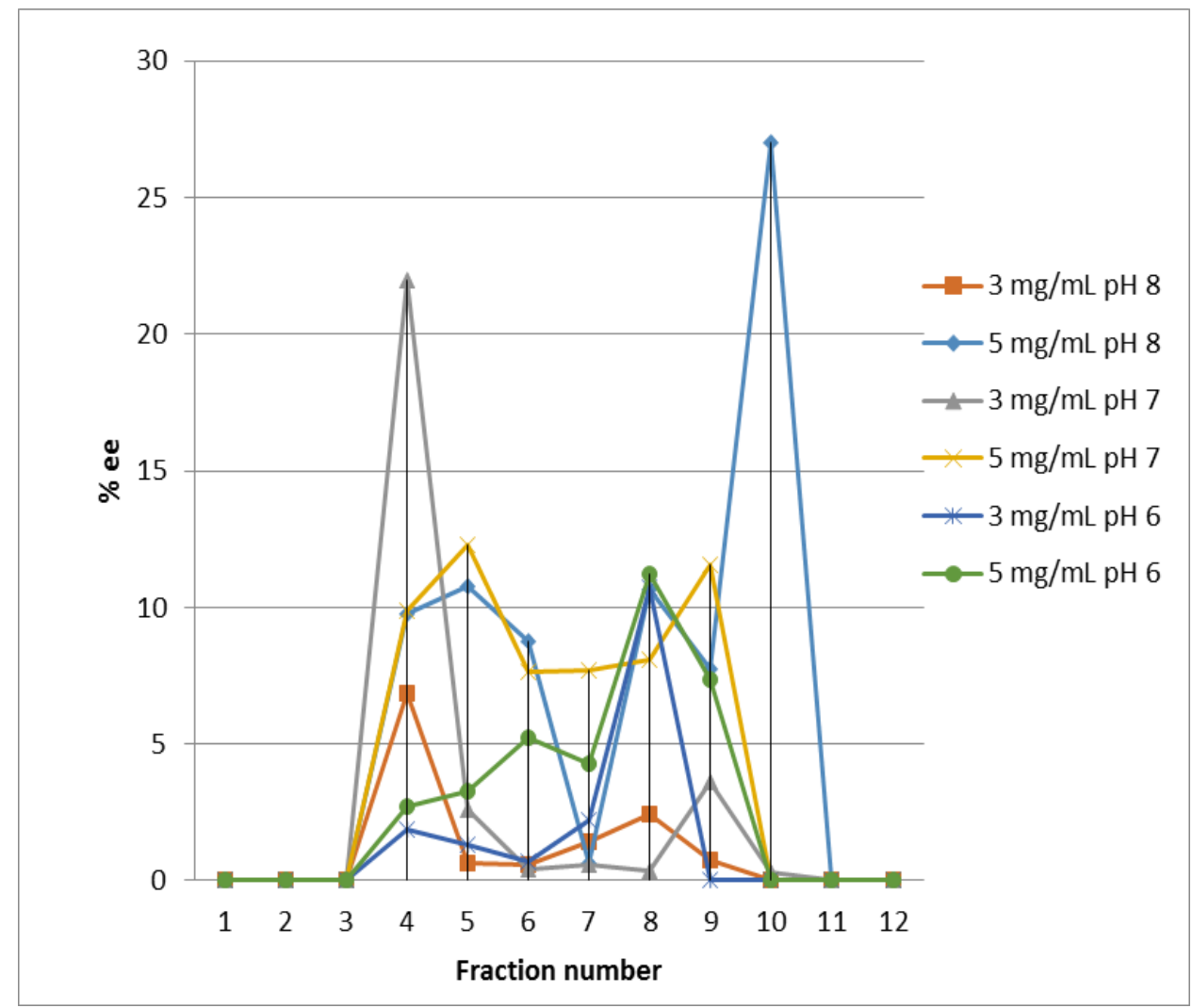

Figure 1. $e$ \% $\%$ values versus different $\mathrm{pHs}$ and the concentration values for MA

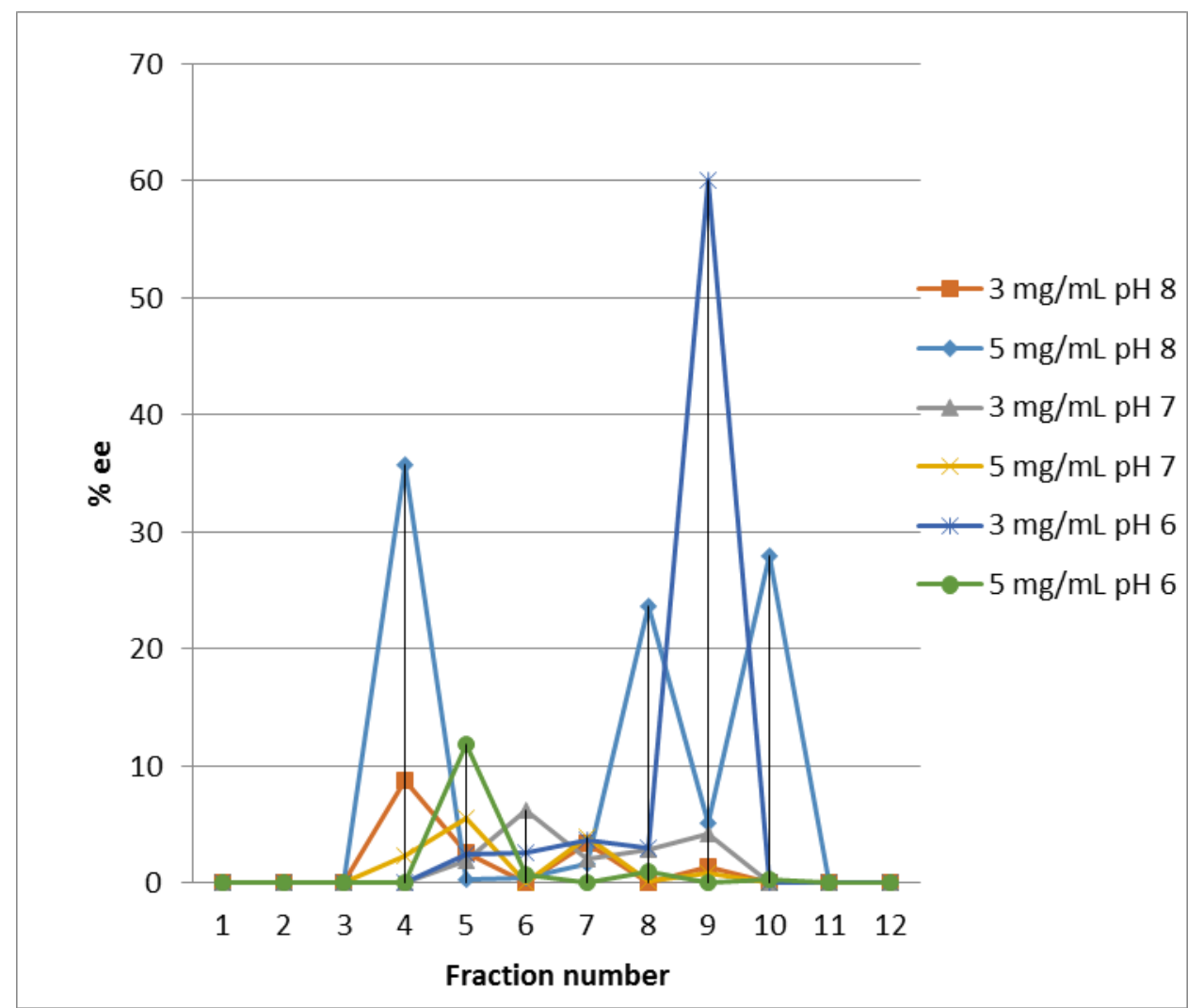

Figure 2. $e e \%$ values versus different $\mathrm{pHs}$ and the concentration values for 2-PPA 
As a result, the separation capacity of the separation column was determined by using rac-MA and 2-PPA. Optimum $\mathrm{pH}$ values were also found, and resolution parameters and ee\% values were calculated for each organic acid. In this study, a significant relationship with regard to resolution yields could not be detected between the studied $\mathrm{pHs}$ and the concentration values. However, it is known that polar amino alcohol and azo groups on chemically modified Sepharose 4B can probably form multipleinteractions with a racemate via hydrogen bonding on the $-\mathrm{OH},-\mathrm{C}=\mathrm{O}$ and $-\mathrm{N}=\mathrm{N}$ - groups, and a dipoledipole interaction on $-\mathrm{C}=\mathrm{O}$ groups (Scheme 4). The $\pi-\pi$ interaction between the phenyl group in the molecular structure of chiral selector and the phenyl group of racemate may also play some role in the chiral separation. Phenyl rings gives high concentrations of $\pi$-delocalized electrons. - $\mathrm{OH}$ and $-\mathrm{N}-\mathrm{H}$ groups of 4a allow dipol stacking and hydrogen bonding. As the orientation is localized towards the matrix surface, some steric hindrance may be encountered. Ethyl group forms a hydrophobic interaction site. ${ }^{41-43}$ (S)-MA shows stronger overall binding and convenient stereochemical approaches to CSP. Hydrophobic ethyl groups form weak Van der Waals interactions with analytes.

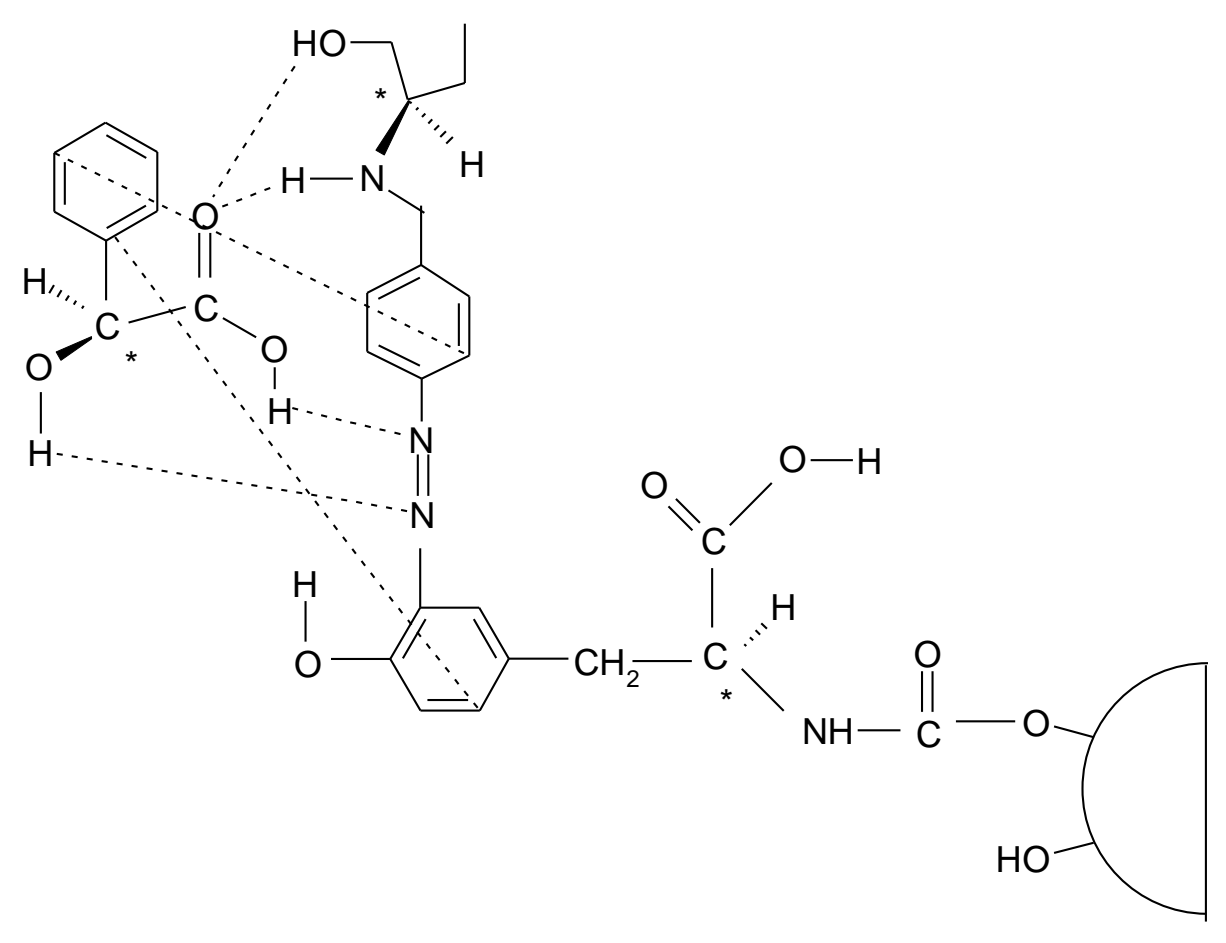

Scheme 4. Presentation of the interactions between analytes and CSP

\subsection{Elucidation of Binding Behavior of Analytes on the CSP by a Docking Process and Quantum Mechanical Methods}

As mentioned before, a docking process was performed to determine settling of analytes through CSP and to detect the enantioselective interactions between analytes and CSP. Autodock4 scores ligands' docking mode by binding free energy calculations. (R)-MA (MA-R) have a docking score of -3.46 $\mathrm{kcal} / \mathrm{mole},(S)$-MA (MA-S) have a docking score of $-3.76 \mathrm{kcal} / \mathrm{mole}$ and $(R)$ and $(S)$ 2-PPA (PP-R and PP-S) have docking scores of $-3.4 \mathrm{kcal} / \mathrm{mole}$ and $-3.44 \mathrm{kcal} / \mathrm{mole}$, respectively. Experimental results show that MA-R leaves column later then MA-S and PP-S leaves column later then PP-R which also mean MA-R and PP-S have better interactions with CSP than other configurations. It has been seen that analytes that have the best interactions with CSP are docked at inner cavity of CSP while analytes that have fewer interactions with CSP are located at outer site of cavity (Figure 3). 


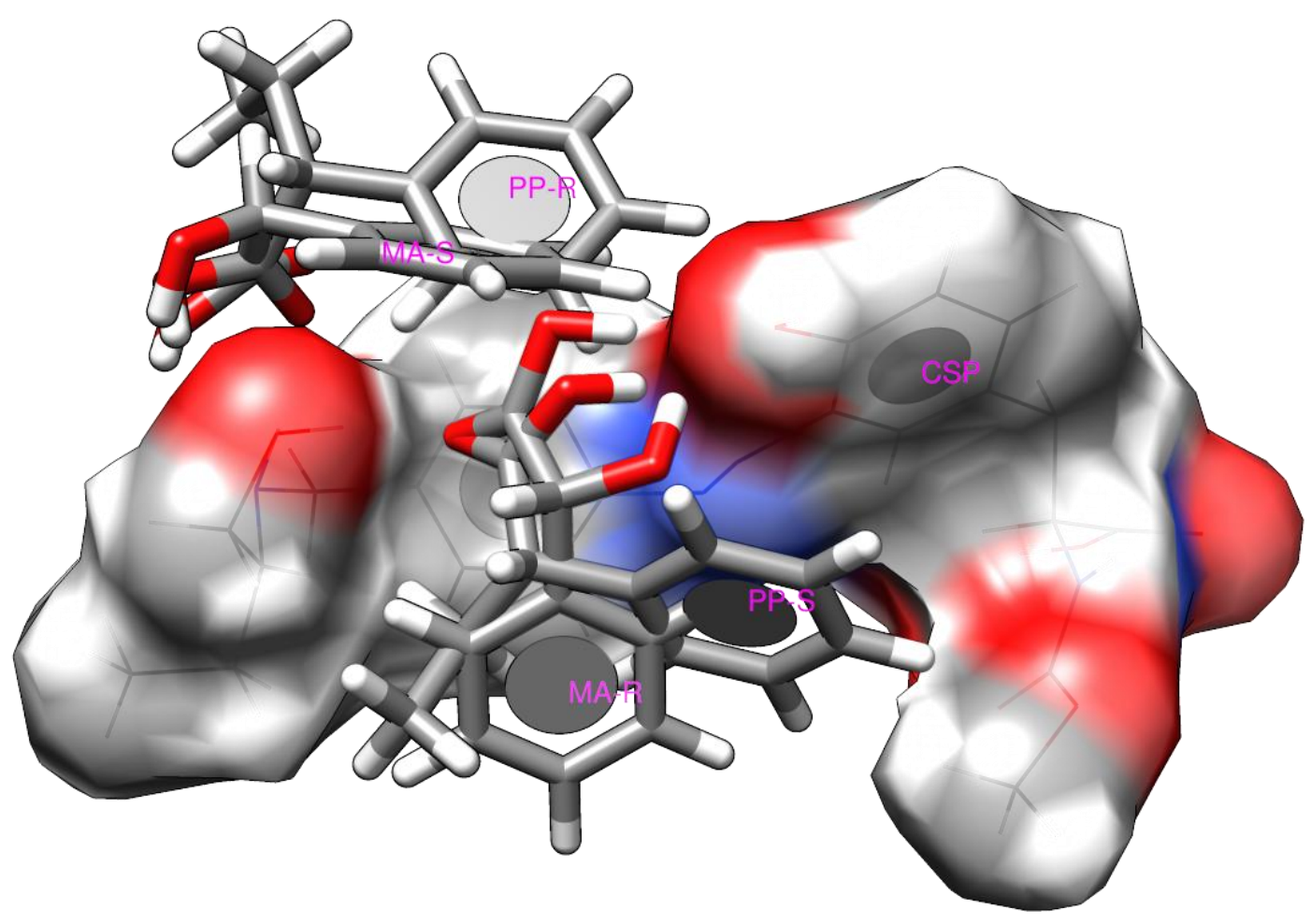

Figure 3. Docking poses of analytes on CSP

It must be noted that MA-S has a slightly better docking score than MA-R while experimental results contrast to this outcome. However, analysis of docking outputs shows that this may be caused by intermolecular energy of MA-R complex that may have greater intermolecular energy, which leads to have a low docking score. Interaction analysis of molecules can offer a better understanding of chiral discrimination of molecules (Figure S 3-6). MA-R molecule forms four hydrogen bonds with CSP. Phenyl group of MA is being in a $\pi$ - $\pi$ stacked interaction with phenyl group of CSP and this phenyl group also contacts with carboxylic acid oxygen of MA by a $\pi$-lone pair interaction. These interactions lead MA-R to leave column later. The MA-S only interacts with two hydrogen bonds with CSP molecule. From the experimental data it is known that PP-S leaves column later than PP-R. Docking results assist this with detailing interactions of these two analytes with CSP. It was shown that PP-S has four hydrogen bonds and a $\pi-\pi$ T shaped interaction between phenyl groups and also a $\pi$ - lone pair interaction with CSP molecule while PP-R has only two interactions with CSP molecule.

After docking process, the complexes are optimized by quantum mechanical methods. By increasing the level of method, all complexes are finally optimized with B3LYP/6-31+G(d) basis set. The calculations show that MA-R and PP-S complexes with CSP have a smaller energy than MA-S and PP-R complexes with CSP, respectively. It is also seen from HPLC chromatogram that MA-R is separated better with MA-S while PP-R and PP-S are more closely positioned to each other. The quantum mechanical computations show that the optimized structure of MA-R interacts with CSP by three hydrogen bonds while MA-S interacts with only one hydrogen bond which allows an accurate separation. However, PP-R and PP-S have same degree of interaction with CSP by only two hydrogen bonds, which decrease the gap of releasing time.

\section{Conclusion}

In the first part of the study; the separation column containing a Pirkle-type CSP was successfully prepared and resolution processes of racemic organic acids on the separation column was carried out in detail. Then, the separation capacity of the separation column was evaluated by determining ee $\%$ of the eluates on CHIRALPAK AD-H chiral column by HPLC. The maximum ee\% for MA and 2-PPA was determined to be 60.84 and 27.4, respectively. Separation factors $\left(\mathrm{k}_{1}, \mathrm{k}_{2}, \alpha\right.$, and Rs) were calculated for 
each acid. In the final part of the study; enantioselective interactions between the Pirkle-type CSP and the analytes have been thoroughly investigated. The reason of lower enantiomeric yield of rac-2-PPA, with respect to rac-MA, was indicated by a docking process and quantum mechanical methods.

\title{
Acknowledgements
}

The authors gratefully acknowledge to the Scientific and Technical Research Council of Turkey (TUBITAK) for financial support (Project No: 110T507). We have declared no conflict of interest. Many thanks for analysis and research support provided by Dicle University Science and Technology Research Center (DUBTAM).

\section{Supporting Information}

Supporting information accompanies this paper on http://www.acgpubs.org/OC

\author{
ORCID \\ Reşit Çakmak: 0000-0003-0401-7419 \\ Selami Ercan: 0000-0002-9528-6122 \\ Murat Sünkür: 0000-0002-8513-7860 \\ Hayrullah Y1lmaz 0000-0002-5275-6606 \\ Giray Topal: $\underline{0000-0002-0585-9688}$
}

\section{References}

[1] Ali, I.; Suhail, M.; Asnin, L., Aboul-Enein, H.Y. Reverse elution order of $\beta$-blockers in chiral separation. J. Liq. Chromatogr. Relat. Technol. 2017, 40, 435-441.

[2] Rathnasekara, R.; El Rassi, Z. Polar silica-based stationary phases. Part II- Neutral silica stationary phases with surface bound maltose and sorbitol for hydrophilic interaction liquid chromatography. $J$. Chromatogr. A. 2017, 1508, 24-32.

[3] Aranyi, I.; Ilisz, I.; Peter, A.; Fülöp, F.; West, C. Exploring the enantioseparation of amino-naphthol analogues by supercritical fluid chromatography. J. Chromatogr. A. 2015, 1387, 123-133.

[4] Christodoulou, A.E. An overview of HPLC methods for the enantiomer separation of active pharmaceutical ingredients in bulk and drug formulations. Curr. Org. Chem. 2010, 14, 2337-2347.

[5] Li, L.; Zhou, S.; Jin, L.; Zhang, C.; Liu, W. Enantiomeric separation of organophosphorus pesticides by high-performance liquid chromatography, gas chromatography and capillary electrophoresis and their applications to environmental fate and toxicity assays. J. Chromatogr. B. 2010, 878, 1264-1276.

[6] Zehani, Y.; Lemaire, L.; Millet, R., Lipka, E. Small scale separation of isoxazole structurally related analogues by chiral supercritical fluid chromatography. J. Chromatogr. A. 2017, 1505, 106-113.

[7] Larsen, R.D.; Corley, E.G.; Davis, P.; Reider, P.J.; Grabowski, E.J.J. $\alpha$-hydroxy esters as chiral reagents: asymmetric synthesis of 2-arylpropionic acids. J. Am. Chem. Soc. 1989, 111, 7650-7651.

[8] Yamamoto, T.; Akai, Y.; Nagata, Y.; Suginome, M. Highly Enantioselective Synthesis of Axially Chiral Biarylphosphonates: Asymmetric suzuki-miyaura coupling using high-molecular-weight, helically chiral polyquinoxaline-based phosphines. Angew. Chem. Int. Edit. 2011, 50, 8844-8847.

[9] Höhne, M.; Kühl1, S.; Robins, K.; Bornscheuer, U.T. Efficient asymmetric synthesis of chiral amines by combining transaminase and pyruvate decarboxylase. Chem. Bio. Chem. 2008, 9, 363-365.

[10] Okamoto, Y.; Yashima, E. Polysaccharide derivatives for chromatographic separation of enantiomers. Angew. Chem. Int. Edit. 1998, 37, 1020-1043..

[11] Gröger, H. nzymatic routes to enantiomerically pure aromatic $\alpha$-hydroxy carboxylic acids: a further example for the diversity of biocatalysis. Adv. Synth. Catal. 2001, 343, 547-558.

[12] Zhang, Y.; Yao, S.; Zeng, H.; Song, H. Chiral separation of pharmaceuticals by high performance liquid chromatography. Curr. Pharm. Anal. 2010, 6, 114-130.

[13] Lin, Y.; Zhou, J.; Tang, J.; Tang, W. Cyclodextrin clicked chiral stationary phases with functionalitiestuned enantioseparations in high performance liquid chromatography. J. Chromatogr A. 2015, 1406, 342346.

[14] J. Zhao, J.; Lu, X.; Wang, Y.; Lv, J. 'Click' preparation of a novel 'native-phenylcarbamoylated' bilayer cyclodextrin stationary phase for enhanced chiral differentiation. J. Chromatogr A. 2015, 1381, 253-259. 
[15] Ashtari, M.; Cann, N.M. The docking of chiral analytes on proline-based chiral stationary phases: A molecular dynamics study of selectivity. J. Chromatogr. A,. 2015, 1409, 89-107.

[16] Gasparrini, F.; Misiti, D.; Villani, C. High-performance liquid chromatography chiral stationary phases based on low-molecular-mass selectors. J. Chromatogr. A. 2001, 906, 35-50.

[17] Wang, Z.; La, B.; Fortunak, J.M. Enantioselective synthesis of $\alpha$-hydroxy carboxylic acids: Direct conversion of $\alpha$-oxocarboxylic acids to enantiomerically enriched $\alpha$-hydroxy carboxylic acids via neighboring group control. Tetrahedron. Lett. 1998, 39, 5501-5504.

[18] Lorenz, H., Sapoundjiev, D.; Seidel-Morgenstern, A. Enantiomeric mandelic acid system melting point phase diagram and solubility in water. J. Chem. Eng. Data. 2002, 47, 1280-1284.

[19] Tulashie, S. K.; Lorenz, H.; Seidel-Morgenstern, A. Solubility of mandelic acid enantiomers and their mixtures in three chiral solvents. J. Chem. Eng. Data. 2010, 55, 5196-5200.

[20] Mao, S.; Zhang, Y.; Rohanl, S.; Ray, A. K. Chromatographic resolution and isotherm determination of $(R, S)$-mandelic acid on Chiralcel-OD column. J. Sep. Sci. 2012, 35, 2273-2281.

[21] Tang, K.W.; Yi, J. M.; Huang, K. L.; Zhang, G. L. Biphasic recognition chiral extraction: a novel method for separation of mandelic acid enantiomers. Chirality, 2009, 21, 390-395.

[22] Okamoto, Y.; Aburatani, R.; Kaida, Y., Hatada, K., Inotsume, N., Nakano, M. Direct chromatographic separation of 2-arylpropionic acid enantiomers using tris (3,5-dimethylphenylcarbamate)s of cellulose and amylose as chiral stationary phases. Chirality, 1989, 1, 239-242.

[23] Bikadi, Z.; Hazai, E. In silico description of differential enantioselectivity in methoxychlor Odemethylation by CYP2C enzymes. Biochim. Biophys. Acta. 2008, 1780, 1070-1079.

[24] Zhao, C.F.; Cann, N.M. Molecular Dynamics study of chiral recognition for the Whelk-O1 chiral stationary phase, Anal. Chem. 2008, 80, 2426-2438.

[25] Zhao, C.F.; Diemert, S.; Cann, N.M. Cann, Rational optimization of the Whelk-O1 chiral stationary phase using molecular dynamics simulations, J. Chromatogr. A. 2009, 1216, 5968-5978.

[26] Marvin was used for drawing chemical structures, Marvin 6.0.2, ChemAxon (http://www.chemaxon.com), (2013).

[27] Dassault Systèmes BIOVIA, Discovery Studio Modeling Environment, Release 4.5, San Diego: Dassault Systèmes, (2015).

[28] Case, D. A.; Darden, T. A.; Cheatham III, T. E.; Simmerling, C. L.; Wang, J.; Duke, R. E.; Luo, R.; Walker, R. C.; Zhang, W.; Merz, K. M.; Roberts, B.; Hayik, S.; Roitberg, A.; Seabra, G.; Swails, J.; Goetz, A. W.; Kolossváry, I.; Wong, K. F.; Paesani, F.; Vanicek, J.; Wolf, R. M.; Liu, J.; Wu, X.; Brozell, S. R.; Steinbrecher, T.; Gohlke, H.; Cai, Q.; Ye, X.; Wang, J.; Hsieh, M. J.; Cui, G.; Roe, D. R.; Mathews, D. H.; Seetin, M. G.; Salomon-Ferrer, R.; Sagui, C.; Babin, V.; Luchko, T.; Gusarov, S.; Kovalenko, A.; Kollman, P. A.; AMBER 12; University of California: San Francisco, (2012).

[29] Morris, G.M.; Huey, R.; Lindstrom, W.; Sanner, M.F.; Belew, R.K.; Goodsell, D.S.; Olson, A. J. AutoDock4 and AutoDockTools4: Automated docking with selective receptor flexibility. J. Comput. Chem. 2009, 30, 2785-2791.

[30] Frisch, M. J.; Trucks, G. W.; Schlegel, H. B.; Scuseria, G. E.; Robb, M. A.; Cheeseman, J. R.; Scalmani, G.; Barone, V.; Mennucci, B.; Petersson, G. A.; Nakatsuji, H.; Caricato, M., Li, X.; Hratchian, H. P.; Izmaylov, A. F.; Bloino, J.; Zheng, G.; Sonnenberg, J. L.; Hada, M.; Ehara, M.; Toyota, K.; Fukuda, R.; Hasegawa, J.; Ishida, M.; Nakajima, T.; Honda, Y.; Kitao, O.; Nakai, H.; Vreven, T.; J. Montgomery, A.; Peralta, Jr., J. E.; Ogliaro, F.; Bearpark, M.; Heyd, J. J.; Brothers, E.; Kudin, K. N.; Staroverov, V. N.; Kobayashi, R.; Normand, J.; Raghavachari, K.; Rendell, A.; Burant, J. C.; Iyengar, S. S.; Tomasi, J.; Cossi, M.; Rega, N.; Millam, J. M.; Klene, M.; Knox, J. E.; Cross, J. B.; Bakken, V.; Adamo, C.; Jaramillo, J.; Gomperts, R.; Stratmann, R. E.; Yazyev, O.; Austin, A. J.; Cammi, R.; Pomelli, C.; Ochterski, J. W.; R. Martin, L.; Morokuma, K.; Zakrzewski, V. G.; Voth, G. A.; Salvador, P.; Dannenberg, J. J.; Dapprich, S.; Daniels, A. D.; Farkas, Ö.; Foresman, J. B.; Ortiz, J. V.; Cioslowski, J.; and Fox, D. J.; Gaussian 09, Revision E.01, Gaussian, Inc., Wallingford CT, (2009).

[31] Pettersen, E.F.; Goddard, T.D.; Huang, C.C.; Couch, G.S.; Greenblatt, D.M.; Meng, E.C.; Ferrin, T.E. UCSF Chimera-A visualization system for exploratory research and analysis. J. Comput. Chem. 2004, 25, 1605-1612.

[32] Domingo, L.R.; Aurell, M.J.; Arno, M.; Saez, J.A. Toward an understanding of the acceleration of Diels-Alder reactions by a pseudo-intramolecular process achieved by molecular recognition. A DFT study. J. Org. Chem. 2007, 72, 4220-4227.

[33] Kaya, M. Resolution of racemic mixtures of 3-hydroxybutanoic acid by Pirkle-type column chromatography, Institute of science of Dicle University, Diyarbakır, 2010.

[34] Yılmaz, H.; Topal, G.; Çakmak, R.; Hoşgören, H. Resolution of ( \pm -beta-Methylphenylethylamine by a novel chiral stationary phase for pirkle-type column chromatography. Chirality 2010, 22, 252-257. 
[35] Özbey, S.; Kaynak, F. B.; Toğrul, M.; Demirel, N.; Hoşgören, H. Synthesis of $R$-(-)-2-ethyl- $N$-benzyl (benzo-monoaza-15-crown-5) and the crystal structure of its sodium perchlorate complex. J. Incl. Phenom. Macrocycl. Chem. 2003, 45, 123-128.

[36] Tarhan, T.; Tural, B.; Tural, S.; Topal, G. Enantioseparation of mandelic acid enantiomers with magnetic nano-sorbent modified by a chiral selector. Chirality 2015, 27, 835-842.

[37] C. Fernandes, C.; Palmeira, A.; Santos, A.; Tritan, M.E.; Afonso, C.M.; Pinto, M. Enantioresolution of chiral derivatives of xanthones on $(S, S)$-whelk-O1 and L-phenylglycine stationary phases and chiral recognition mechanism by docking approach for $(S, S)$-Whelk-O1. Chirality 2013, 25, 89-100.

[38] Pirkle, W.H.; Hyun, M.H.; Bank, B. A rational approach to the design of highly-effective chiral stationary phases. J. Chromatogr. A. 1984, 316, 85-604.

[39] Pirkle, W.H.; Pochapsky, T.C.; Mahler, G.S., Field, R.E. Chromatographic separation of the enantiomers of 2-carboalkoxyindolines and $N$-aryl- $\alpha$-aminoesters on chiral stationary phases derived from $N$-(3,5dinotrobenzoyl)- $\alpha$-amino acids. J. Chromatogr. A. 1985, 348, 89-96.

[40] Hyun, M.H.; Min, C.S.; Cho, Y.J. Examples of liquid chromatographic resolution of $\pi$-acidic racemates on a $\pi$--acidic chiral stationary phase. J. High. Resol. Chromatogr. 1995, 18, 63-65.

[41] Chen, X.; Yamamoto, Y. Polysaccharide derivatives as useful chiral stationary phases in high-performance liquid chromatography. Pure. Appl. Chem. 2007, 79, 1561-1573.

[42] Yu, J.; Tang, J.; Yuan, X.; Guo, X.; Zhao, L. Evaluation of the chiral recognition properties and the column performances of three chiral stationary phases based on cellulose for the enantioseparation of six dihydropyridines by high-performance liquid chromatography. Chirality 2017, 29, 147-154.

[43] Xie, S.M.; Yuan, L.M. Recent progress of chiral stationary phases for separation of enantiomers in gas chromatography. J. Sep. Sci. 2017, 40, 124-137.

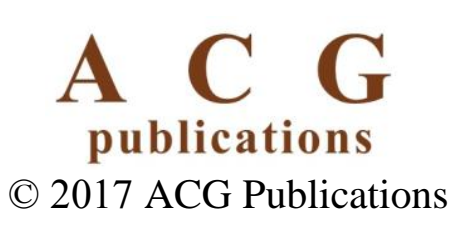

